\title{
Analysis of the Constructive Features of the Earth Dam
}

\author{
Mikhail Balzannikov ${ }^{1, *}$ \\ ${ }^{1}$ Samara State University of Economics, 443090 Samara, 141 Sovetskoi Armii St, Russia
}

\begin{abstract}
The article considers the earth dam of the run-of-river unit Kuibyshev hydroelectric power station on the Volga river (Russia). The main parameters of the earth dam, peculiarities of its erection and operation are described. The article notes the importance of ensuring a high degree of reliability of water structures constructed near major cities. It is especially important to monitor the condition of retaining structures with long service life. The factors influencing the change of the initial design conditions of operation of the Kuibyshev run-of-river unit dam are discussed. The results of examination of the geometric parameters of the body of the dam, performed at different periods of its maintenance, are analyzed. Examination results revealed significant deviations of the elevation marks of the earth dam surface on the upstream side from the design values. Possible causes of the discrepancy between these parameters and the design solutions are considered. The conclusion is drawn that the most likely reason for these features of the dam design lies in the initial incompleteness of construction. The measures for carrying out repair work to improve the reliability of the earth dam are being recommended.
\end{abstract}

\section{Introduction}

At present, ensuring reliable operation of retaining water structures is a very urgent requirement for both operating enterprises and design organizations [1, 2]. Such an approach has undoubtedly acquired a much higher priority than the traditional requirements for maintaining high indicators of the economic efficiency of the facilities.

This requirement is of particular importance in relation to earth dams of large run-ofriver units constructed in the central regions of Russia on plain full-flowing rivers [3-5]. The proximity of large cities is the reason for special attention to the reliability of such facilities and their safe operation.

As an example, to the north of Samara City, close to Togliatti and Zhigulevsk, Kuibyshev hydroelectric power station was constructed. It is recently often referred to as Zhiguli power station - by the name of the company managing the waterworks.

The station was built in the period from 1950 to 1957, and in the cascade of the VolgaKama hydroschemes served as the sixth stage. The station facilities layout, with the main facilities and their key parameters, are described in detail in [3]. Putting the Kuibyshev hydroelectric station into operation was of great economic importance both for agriculture,

\footnotetext{
*Corresponding author: mibsgasu@mail.ru
} 
as it provided an opportunity to irrigate the arid areas of the region, and for the region's industry due to cheap electric power supply available for enterprises. Besides, the rising water level in the Volga River, due to filling of the reservoir, significantly improved its navigability and water transport operation. Later, the construction of an overpass on pressure structures of the hydroelectric complex allowed to establish railway and automobile service between the banks (figure 1).

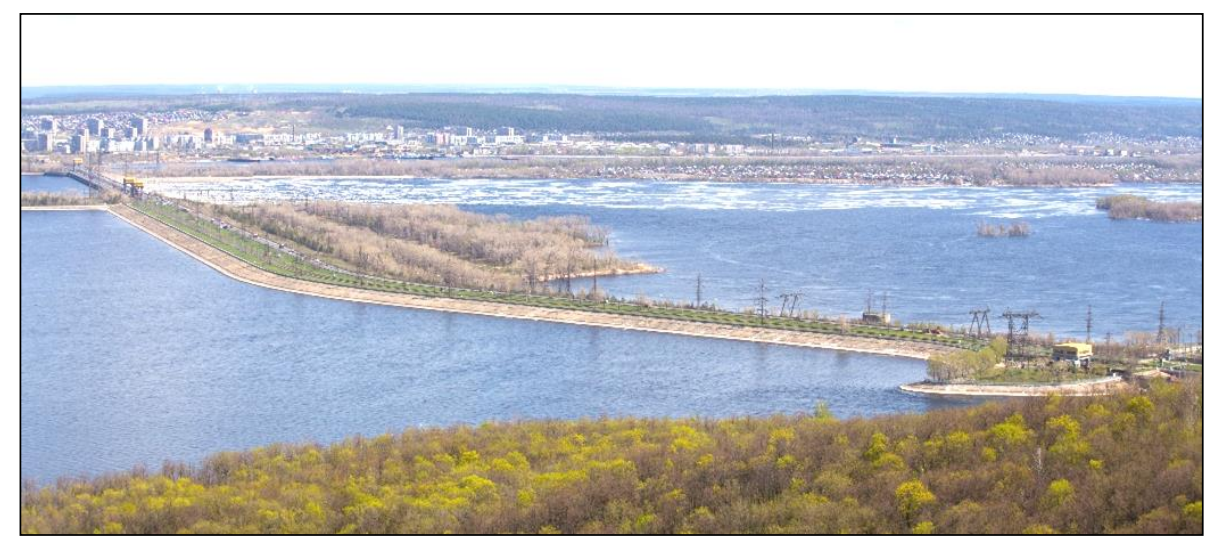

Fig. 1. General view of pressure structures of the hydroelectric complex [6].

The earth dam of the Kuibyshev hydroelectric complex deserves to be called one of the unique hydrotechnical objects of that time. It has a considerable length of about $2800 \mathrm{~m}$ and a large height of $50 \mathrm{~m}$ within the channel part, and $27 \mathrm{~m}$ - in the floodplain [3]. The dam was erected by hydromechanization means, without anti-filtration devices, by filling with fine-grained sands (figure 2), so its body is homogeneous.

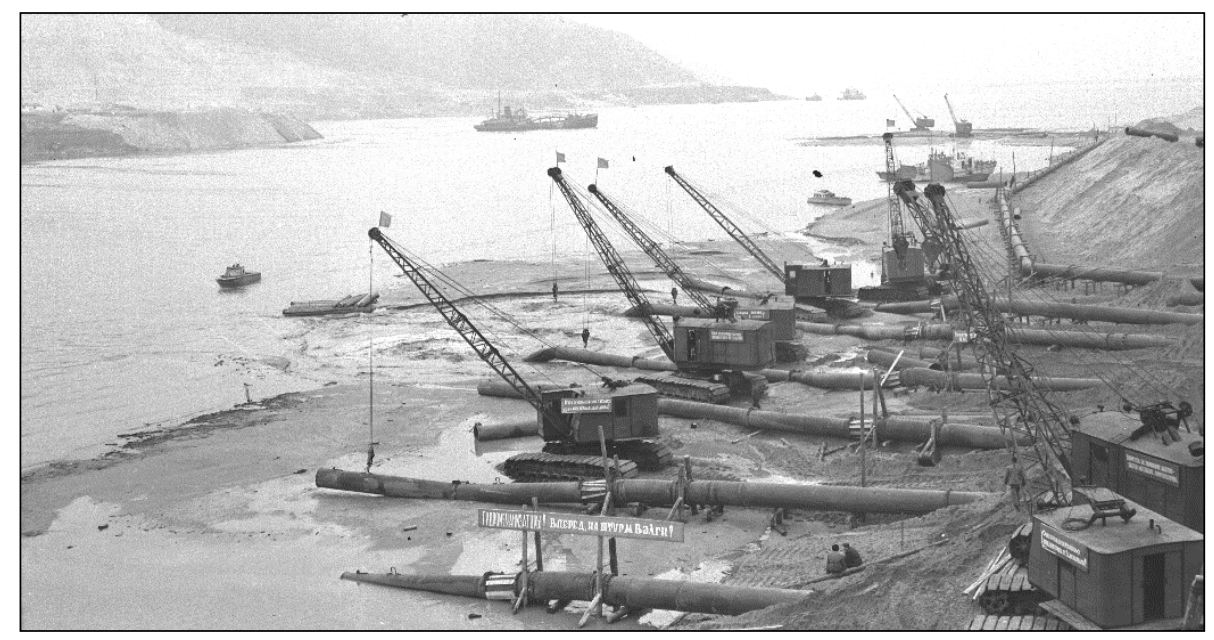

Fig. 2. Construction of an earth dam [6].

To fulfill the requirements ensuring the stability of slopes, the dam is constructed with a highly flattened cross profile. The slope of the body of the dam from the side of the reservoir is supported by concrete plates with top view dimensions of $10 \times 10 \times 0.50 \mathrm{~m}-$ in the zone of wave action, and 10x10x0.35 m - above the zone of wave action. The lower part of the slope and the horizontal sections are fixed by the rock mass. On the downstream side, the upper part of the dam slope is fixed by a layer of crushed stone $0.2 \mathrm{~m}$ thick, and the 
lower part - by a stone layer $1 \mathrm{~m}$ thick by the principle of reverse filter.

During the period of its long-term operation, the working conditions of the Kuibyshev hydroelectric complex dam have changed significantly. Examples of such changes are as follows.

First, filling of the Saratov Reservoir in 1967-1970 led to an increase in the water level in the downstream of the Kuibyshev power station by more than $1 \mathrm{~m}$. Such a change in the water level in the downstream led to a reduction of pressure and a decrease in the electricity generation. Besides, and more important, the high-altitude position of the surface curve of the filtration flow in the body of the earth dam has changed. Such a rise of groundwater in the body of a dam is very dangerous and may cause a decrease in the stability of the lower slope of the dam.

Second, with the operation of the earth dam, its filtration properties change, because the physical and mechanical properties of the ground that make up the body of the dam alter due to colmatation. Such changes may also cause a rise in the high-altitude positions of the surface curve of the filtration flow.

Third, in the last decade, the load from rail and road transport has increased considerably due to the increase in the throughput capacity of the transport crossing over the dam. Increasing load caused by motor vehicles, resulting in an increasing dynamic impact on the earth dam, together with water saturating the body of the dam, in turn, can also significantly reduce the stability and strength of the dam.

In connection with these circumstances, constant monitoring of the dam condition and the analysis of structural deformations turn to be very important organizational measures of ensuring safe operation of the earth dam.

\section{Materials and Methods}

Inspections of the earth dam, for the purpose of determining changes in the design parameters, are performed on a regular basis. Measuring is conducted with the use of underwater equipment - a single-beam echo sounder and a side-scan sonar. Equipment has been installed on the boat. The results of the measurements have been presented graphically in the form of the dam profiles and surface maps.

\section{Results}

The inspections [3] showed that the upper slope profiles (22 in total) of the earth dam of Kuibyshev hydro power plant contain sections and separate zones with elevations significantly different from the design values. The following deviations of the elevation marks were registered downward: for profile No. 2 - up to $2.8 \mathrm{~m}$; for profile No. 3 - up to $2.6 \mathrm{~m}$; for profile No. 4 - up to $3.2 \mathrm{~m}$; for profile No. 5 - up to $6.8 \mathrm{~m}$; for profile No. 6 - up to $5.0 \mathrm{~m}$. At the same time, these deviations are not point, but extended. For example, for profile No. 2, the height difference of at least $0.6 \mathrm{~m}$ extends for as long as about $30 \mathrm{~m}$, and for profile No. 3, the difference in the altitude marks of no less than $2.6 \mathrm{~m}$ - for as long as $90 \mathrm{~m}$. For profile No. 4, the difference in elevations of no less than $3.2 \mathrm{~m}$ is registered for as long as $37 \mathrm{~m}$. The worst case is observed in profiles No. 5 and No. 6, where the deviations of 6 and $10 \mathrm{~m}$ are registered for as long as 87 and 105 meters, respectively.

Authors [3] also point out that the deviations of the elevation marks of the earth dam were described earlier in the course of inspection in 1958. Moreover, the dam profile has barely changed over the last few years.

Thus, it is important to understand what caused such changes and what measures should be taken now to ensure the reliability of the structure. 


\section{Discussion}

As a possible reason for the noted discrepancies in the dam profile, the following is stated [3]. The longitudinal axis of the earth dam in top view is significantly fractured. This circumstance caused the inclined water supply to the power station units. The angle between the axis of the station supply channel and the axis of the earth dam is about $50^{\circ}$ (figure 3). During the initial period of the dam operation, these features led to significant alongshore stream velocities, which could cause erosion of the body of the dam. In addition, authors point to the possible destructive effects of waves, as well as vertical and horizontal whirlpools.

The analysis of the operating conditions of the earth dam in the first years of operation, carried out by the author, showed that the abovementioned factors could not have such a significant destructive effect.

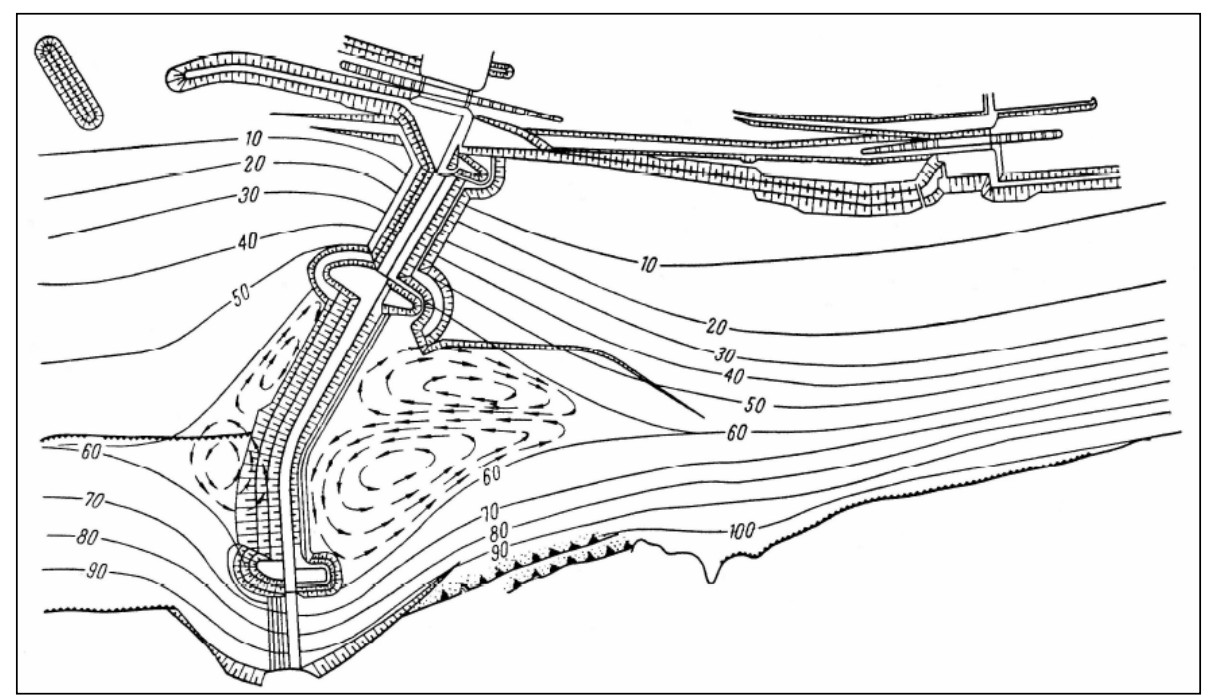

Fig. 3. Flow plan [3].

Indeed, this assumption does not take into account the actual data on the water discharged through the hydropower plant aggregates during the analyzed period. Thus, figure 4 shows the graph of the water flow through the structures of the hydrosystem in the spring-summer period of 1956, according to [3]. The graph proves that the maximum flow of up to 10-13 thousand cubic meters passed through the power station unit only in April 23-26, and after May 11, the discharge did not exceed 1.2 thousand cubic meters. Note that the cross-sectional area in the narrowest part of the power station supply channel, which can be exemplified as the channel cross-section along the ridge of the flooded bridge, was about $7500 \mathrm{~m}^{2}$.

Thus, the average flow velocity in the supply channel of the power station was $10,000 / 7593=1.32 \mathrm{~m} / \mathrm{s}$ for 4 days. Further, by mid-May of the same year, the average flow velocity decreased quickly to a value of $1200 / 7593=0.16 \mathrm{~m} / \mathrm{s}$. It is worth mentioning that the largest velocities are usually observed in the central part of the stream where depths are the greatest. In the coastal zone, the flow is usually slower. The velocities of the water flow along the coastal current near the slope of the dam near profiles No. 5-6, obviously, were even smaller. The abovementioned velocities, most of the time (except for a few days), were below the erosion values, which for fine sands are $0.2-0.4 \mathrm{~m} / \mathrm{s}$. 


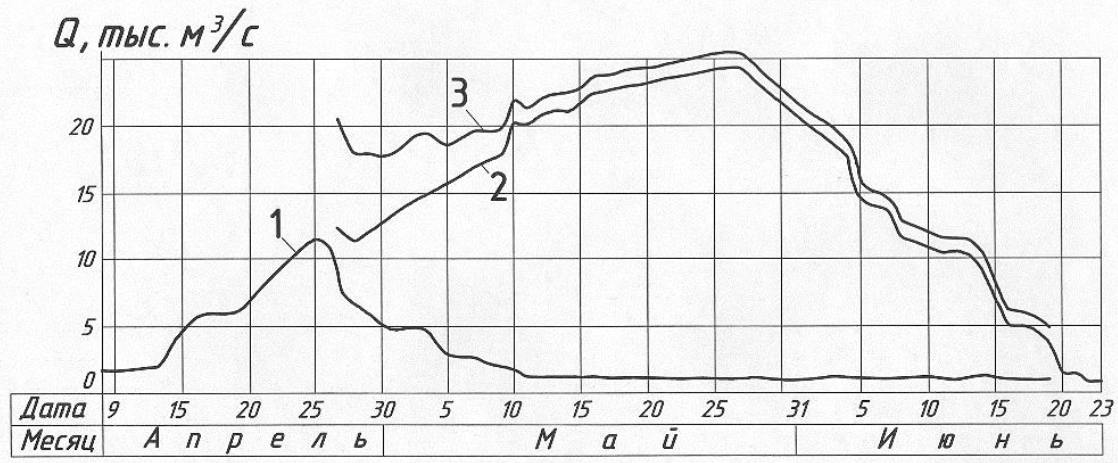

Fig. 4. The schedule of flood discharge through the structures of the Kuibyshev hydroelectric complex in 1956: 1 - water flow through the station building, 2 - through the weir dam; 3 - total discharge.

Moreover, the significance of waves as a source of destructive impact on the slope of the dam is exaggerated. Waves on the water surface are caused by the wind. The parameters of wind waves depend on a number of factors, the most important of which are wind speed and fetch. The analysis of wind speeds around the Kuibyshev hydroelectric power station showed that, in summer, the probability of winds with speed exceeding $8 \mathrm{~m} / \mathrm{s}$ amounts to only 5\%. It should also be taken into account that in the summer-autumn period of 1956 the reservoir was only partially filled. The reservoir water level was about $45.0 \mathrm{~m}$, which is much lower than the normal topwater level of $53.0 \mathrm{~m}$. At this water level, the reservoir's dimensions (primarily the length) are much smaller than the design value. This means that the fetch is also much shorter. The noted circumstances strongly diminish the destructive role of wind waves and their impact on the earth dam over a very short period of time.

Based on the analysis performed, we can conclude that the abovementioned explanation considering significant deviation of the profile and elevation marks of the earth dam upper slope from the design values in the short period of its initial operation is inconsistent. Other possible causes should be considered.

In particular, the most probable cause of the discrepancy in the profile of the dam, already observed in 1958, may be the initial incompleteness of its construction, i.e. originally the dam was erected not reaching its full design profile. In fact, huge amounts of excavation work carried out over a large area due to the flattened cross-section of the dam, a large number of construction equipment, very short construction time and time constraints for filling the reservoir in order to launch the hydroelectric units of the power station as soon as possible, could become the reasons why some parts of the dam were not erected up to their full design profile.

There are other (but less likely) reasons. For example, the subsidence of the ground from which the body of the dam was erected due to its constant overmoistening by groundwater. The presence of various soils in the body of the dam, which could affect the amount of subsidence that took place, are also worth mentioning.

In any case, the observed inconsistencies of the actual profile of the earth dam compared to its design do not play a positive role or add confidence in maintaining and improving its operational reliability.

At present, special attention is paid to ensuring the reliability in relation to water engineering structures $[7,8]$. Therefore, it seems advisable to recommend the implementation of works aimed at adjusting parts of the upper slope surface to fit its design position. Certain technological solutions can be applied here, namely, the pouring of sandy 
soil into areas directly under water from water transport until the design levels are reached. It is possible to additionally cover the areas of the surface over the poured soil with crushed stone or use new progressive developments [9, 10]. The proposed measures will undoubtedly improve the filtration conditions and increase the operational reliability of the dam.

\section{Conclusions}

The main conclusions of the research can be formulated as follows

1. For the water engineering facilities within large hydroschemes constructed in the $50 \mathrm{~s}$ of the last century on flat rivers, the operating conditions can change significantly over time if compared with the design solutions. These changes can adversely affect the reliability of the facilities. Thus, it is very important to constantly monitor the condition of the facilities and take measures to increase their operational reliability.

2. The performed analysis of the inspection results concerning the geometric parameters of the body of the earth dam of the Kuibyshev hydroelectric complex and revealed deviations in the elevation marks of the upper slope of the dam showed that the most probable cause of the observed inconsistencies in the elevation marks of the dam upper slope is its initial incompleteness of structure compared to the full design profile, determined by the short terms of construction and a rigid time schedule for filling the reservoir for launching hydroelectric units of the hydroelectric power station.

3. The repair works aimed at adjusting the sections of the top surface of the dam to their design position are recommended to improve the operational reliability of the earth dam.

\section{References}

1. M.I. Balzannikov, B.G. Ivanov, A.A. Mikhasek, Vestnik MSCU 7, 119-124 (2012)

2. F. Svitala, Yu.M. Galitskova, S.V. Evdokimov, Industrial and Civil Engineering 12, 87$90(2014)$

3. A.A. Romanov, Zhiguli Hydroelectric Power Station. Operation of Water Structures (Samara: Agni Publishing House. 2010)

4. M.I. Balzannikov, M.V. Rodionov, Y.E. Senitsky, Privolzhsky Scientific Journal 2, 35$40(2012)$

5. V.S. Kuznetsov, S.Y. Ladenko, Hydrotechnical construction 10, 11-20 (2015)

6. M.I. Balzannikov, Urban Construction and Architecture 1, 62-70 (2015)

7. V.Y. Zharnitsky, E.V. Andreev, Higher Education Bulletin. Geodesy and Aerial Photography 1, 42-47 (2013)

8. A.A. Mikhasek, M.V. Rodionov, Construction of Unique Buildings and Structures 7, 20-29 (2013)

9. M.I. Balzannikov, M.V. Rodionov, International journal on Hydropower and Dams 6, 60-63 (2013)

10. M.I. Balzannikov, M.V. Rodionov, M.G. Litvinova, Procedia Engineering 153, 77-82 (2016) 